\title{
Snail1 expression in colorectal cancer and its correlation with clinical and pathological parameters
}

\author{
Feride Kroepil ${ }^{\text {* }}$, Georg Fluegen ${ }^{1}$, Daniel Vallböhmer ${ }^{1}$, Stephan E Baldus², Levent Dizdar ${ }^{1}$, Andreas M Raffel', \\ Dieter Hafner ${ }^{3}$, Nikolas H Stoecklein ${ }^{1}$ and Wolfram T Knoefel ${ }^{1}$
}

\begin{abstract}
Background: Snail1 is a transcription regulator of E-cadherin. The loss of E-cadherin seems to be a crucial step in the process of Epithelial-mesenchymal transition (EMT). EMT initiates invasion and proliferation in many tumours. Overexpression of Snail1 is known to be associated with poor outcome in several solid tumours. The aim of this study was to analyse its expression profile and prognostic significance in colorectal cancer.

Methods: Tissue microarrays (TMA) containing paraffin-embedded primary colorectal cancer (CRC) tissue samples from 251 patients were used in this study. The expression of Snail1 and E-cadherin was assessed by

immunohistochemistry in different tumour compartments, corresponding lymph node metastases and normal colonic mucosa. Intensity of staining was classified according to the Remmele score (standardized scoring system) as well as the semiquantitative score established by Blechschmidt et al.

Results: Snail 1 expression was observed in $76 \%$ of the CRC. Loss of E-cadherin was noted in $87 \%$ of the CRC. Snail 1 positive tumours were significantly correlated with Snail 1 positive lymph node metastases $(p=0.03)$. There was no significant correlation between loss of E-cadherin and Snail1 expression, or between N-stage or grading and Snail1 expression. Kaplan-Meier survival analysis identified no prognostic impact of Snail1 expression on overall survival.

Conclusion: Snail1 expression was detectable in most of the CRC but showed no significant association with E-cadherin loss, clinical pathological characteristics or overall survival. The observed loss of E-cadherin could be explained by effects of other important EMT pathways, such as the Wnt-signalling cascade.
\end{abstract}

Keywords: Snail1, E-cadherin, Colorectal carcinoma, Prognostic factor, EMT

\section{Background}

Snail1 was the first characterized repressor of the invasion suppressor gene CDH1, which encodes for the crucial adhesion protein E-cadherin [1,2]. Snail1 can bind to specific E-box regions on the $\mathrm{CDH} 1$ promotor, thus leading to transcriptional repression of E-cadherin. E-cadherin is a member of a family of transmembrane glycoproteins that mediate intercellular adhesion [3]. Loss of its expression or function diminishes cell-cell contacts and is known to be a key step during the process of Epithelial-mesenchymal transition (EMT). EMT describes

\footnotetext{
* Correspondence: Feride.Kroepil@med.uni-duesseldorf.de

'Department of Surgery (A), Heinrich-Heine-University and University Hospital Duesseldorf, Düsseldorf 40225, Germany

Full list of author information is available at the end of the article
}

a phenotypic change in cells from epithelial to mesenchymal properties. By activating this process epithelial cells can dispose of their differentiated characteristics and gain mesenchymal features such as invasiveness, motility and increased apoptotic resistance [4]. This reversible EMT process is crucial in embryonic development for the correct implantation of the embryo and during gastrulation and organogenesis [5,6]. In differentiated somatic cells this programme of EMT is normally inactive [6]. Reactivation of this programme is known to be a crucial event in tumour progression. During this process, cancer cells change their phenotype from epithelial to mesenchymal and gain the ability to invade and metastasize. E-cadherin expression is frequently downregulated in many different types of tumour, where

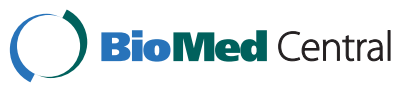


it accompanies the invasiveness and metastatic behaviour of malignant cells [6,7].

Besides their involvement in EMT, Snail family members are involved in a variety of other processes, such as apoptosis or mesoderm formation in the developing embryo. Snail1 has recently been shown to activate Wnt/beta-Catenin signalling and nuclear factor kappa $B$ activity [8,9], and it abrogates the inhibition of the Wnt/beta-Catenin pathway caused by the anti-tumoural compound 1a,25-dihydroxyvitamin D3 [10]. In several entities of human cancer, including skin [11], oral [12], breast [13], hepatocellular [14], gastric [15] and colon carcinomas [16], Snail1 is upregulated and frequently associated with invasiveness, metastases and poor prognosis $[17,18]$. The mechanism by which Snail1 influences these different cellular processes is still not totally understood.

Snail1 RNA is not detectable in normal colon mucosa, but is upregulated in $60-70 \%$ of colorectal adenoma and colorectal cancers (CRC) [16,19-21]. Importantly, aberrant Snail1 expression in CRC was associated not only with poor prognosis, but also with shortened relapsefree survival [20,22]. The tumour microenvironment, especially at the invasive front, is important for the formation of tumour buds in CRC. At the invasive front of CRC, the existence of tumour budding (TB: the detachment and migration of small clusters of tumour cells from the neoplastic epithelium) is correlated with a high incidence of local invasion and distant metastasis. In a recently published study of stage II CRC tissues, TB was associated with increased levels of Snail1 expression as well as a high incidence of metachronous lymph node metastasis. Interestingly, treatment with recombinant TGF- $\beta 1$ increased the number of cells expressing CD133 and Snail1 [23].

Despite the fact that many valuable studies concerning Snail1 expression in CRC have been published, its incidence and its prognostic significance in colorectal cancer remain undetermined.

In order to investigate the expression profile of Snail1 in CRC, we assessed its expression in formalin-fixed and paraffin-embedded (FFPE) tissue samples of 251 patients. We tested the association between the expression of Snail1 and E-cadherin. Furthermore, different tumour compartments (tumour centre and invasion front) and histopathological as well as clinical aspects were considered.

\section{Methods}

\section{Tissue samples and data acquisition}

Paraffin-embedded tissue samples of 251 patients with CRC were obtained from the Institute of Pathology for immunohistochemical analysis. The specimens were previously fixed in 10\% formaldehyde, according to established methods [24]. All tissues were verified and graded in the pathology department. Tumour grading was performed according to World Health Organization (WHO) standards. The samples were randomly selected by experienced pathologists (S.E.B) from the archives of the Department of Pathology of the University Hospital Duesseldorf based on the availability of follow-up data. All patients underwent curative surgery at the University Hospital Duesseldorf between 1996 and 2005. Patients with neoadjuvant therapy, extended lymphatic dissemination (N3), distant metastasis $(\mathrm{M}+)$ or incomplete resection (R1, R2) were excluded from the cohort. Overall survival data were retrieved from a prospectively maintained clinical database at our hospital.

\section{Ethics statement}

The study was approved by the Ethics Committee of the Medical Faculty of the Heinrich-Heine University Düsseldorf.

\section{Tissue microarrays}

Fourteen tissue microarrays (TMA) were used in this study. The TMAs contained paraffin-embedded primary CRC tissue, lymph node metastases and normal colonic tissue samples from archival patient specimens. Up to six cylinders of $1.0 \mathrm{~mm}$ diameter (two from cancer invasion front, two from inner tumour mass, one from normal tissue and one from lymph node metastases, if present) were taken from representative areas of donor blocks of each patient and transferred to paraffin recipient blocks, with $0.5 \mathrm{~mm}$ between each cylinder.

The clinicohistopathological characteristics of the colorectal cancer patients, including age at diagnosis, tumour stage, and histopathological grading, are summarized in Table 1. The difference in sample numbers between Snail 1 and E-cadherin staining (251 vs. 250 ) is due to loss of one sample during staining.

\section{Immunohistochemistry}

Serial $4 \mu \mathrm{m}$ sections of TMA blocks were prepared on a microtome (Leica SM2000R).

For immunostaining, the slides were deparaffinised and epitopes were retrieved using Dako Retrieval Solution (Dako Cytomation, USA) at $95^{\circ} \mathrm{C}$ for $30 \mathrm{~min}$, followed by cooling to room temperature for $20 \mathrm{~min}$. Endogenous peroxidase was inactivated using $0.3 \% \mathrm{H}_{2} \mathrm{O}_{2}$ for $30 \mathrm{~min}$ at room temperature. Subsequently, the sections were rinsed twice in phosphate buffered saline (PBS, pH 7.4) for $5 \mathrm{~min}$. Immunostaining was performed with antibodies directed against E-cadherin (mouse monoclonal, $2 \mu \mathrm{g} / \mathrm{ml}$ ) and Snail1 (rabbit polyclonal, $1 \mu \mathrm{g} / \mathrm{ml}$ ). See Table 2. Incubation with the primary antibodies was performed in a moist chamber at room temperature for 30 min. The Vectastain $A B C$ peroxidase kit was used according to the manufacturer's instructions (Vector 
Table 1 Characteristics of the TMA collective

\begin{tabular}{|c|c|c|c|c|c|}
\hline & & \multicolumn{2}{|c|}{ Patients } & Snail positive & $\begin{array}{c}\text { E-Cadherin } \\
\text { positive }\end{array}$ \\
\hline \multicolumn{6}{|c|}{ Tissue: } \\
\hline & Tumor & \multicolumn{2}{|c|}{251} & $76 \%$ & $61 \%$ \\
\hline & Lymphnode & \multicolumn{2}{|c|}{47} & $70 \%$ & $48 \%$ \\
\hline \multicolumn{6}{|c|}{ Tumorstage: } \\
\hline \multirow[t]{4}{*}{$\mathrm{T}$} & 1 & $8 / 251$ & (3\%) & $75 \%$ & $50 \%$ \\
\hline & 2 & $64 / 251$ & $(26 \%)$ & $84 \%$ & $67 \%$ \\
\hline & 3 & $153 / 251$ & $(61 \%)$ & $74 \%$ & $60 \%$ \\
\hline & 4 & $26 / 251$ & $(10 \%)$ & $69 \%$ & $58 \%$ \\
\hline \multirow[t]{3}{*}{$\mathrm{N}$} & 0 & $146 / 251$ & $(58 \%)$ & $80 \%$ & $64 \%$ \\
\hline & 1 & $64 / 251$ & $(26 \%)$ & $70 \%$ & $59 \%$ \\
\hline & 2 & $41 / 251$ & $(16 \%)$ & $76 \%$ & $54 \%$ \\
\hline \multirow[t]{2}{*}{ M } & 0 & $251 / 251$ & $(100 \%)$ & $76 \%$ & $61 \%$ \\
\hline & 1 & $0 / 251$ & (0\%) & $0 \%$ & $0 \%$ \\
\hline \multirow[t]{3}{*}{ G } & 1 & $2 / 251$ & $(1 \%)$ & $100 \%$ & $50 \%$ \\
\hline & 2 & $209 / 251$ & $(83 \%)$ & $75 \%$ & $64 \%$ \\
\hline & 3 & $40 / 251$ & $(16 \%)$ & $83 \%$ & $50 \%$ \\
\hline \multicolumn{6}{|c|}{ Sex: } \\
\hline & female & $103 / 251$ & $(41 \%)$ & $75 \%$ & $52 \%$ \\
\hline & male & $148 / 251$ & (59\%) & $77 \%$ & $67 \%$ \\
\hline \multicolumn{6}{|c|}{ Age at diagnosis: } \\
\hline & $\leq 65 y$ & $80 / 251$ & $(32 \%)$ & $78 \%$ & $60 \%$ \\
\hline & $>65 y$ & $171 / 251$ & $(68 \%)$ & $75 \%$ & $62 \%$ \\
\hline
\end{tabular}

Lab, USA) for specific antibody binding. Isotype controls using MOPC-21 (mouse IgG1, $2 \mu \mathrm{g} / \mathrm{ml}$ ) and X0903 (rabbit immunoglobulin fraction, $1 \mu \mathrm{g} / \mathrm{ml}$ ) were carried out on serial sections of each sample. Diaminobenzidine (Liquid DAB, Dako Cytomation, USA) was used to stain the bound immunocomplex. All specimens were counterstained with haematoxylin and eosin. A semiquantitative evaluation was performed by two independent researchers using a Zeiss Axioskope.

\section{Evaluation of immunostaining}

The sections were examined by two independent researchers. Tissue samples from spleen and placenta embedded in the TMA were used as an internal control of staining efficiency and evaluation. Immunohistochemical

Table 2 Concentration and supplier of the antibodies

\begin{tabular}{lll}
\hline Antibody & Concentration & Supplier \\
\hline E cadherin (NCH-38) & $2 \mu \mathrm{g} / \mathrm{ml}$ & DAKO \\
Snail1 (Ab17732) & $1 \mu \mathrm{g} / \mathrm{ml}$ & AbCam \\
Mouse lgG1 (MOPC-21) & $2 \mu \mathrm{g} / \mathrm{ml}$ & Sigma \\
Rabbit-lgG (X0903) & $1 \mu \mathrm{g} / \mathrm{ml}$ & DAKO \\
\hline
\end{tabular}

results were evaluated for nuclear (Snail1) and membrane (E-cadherin) -specific staining only.

For E-cadherin and Snail1 an immunoreactive score (IRS) was set up, following Remmele et al. [25]. The level of staining intensity (SI) was subdivided into four groups: 0 (negative), 1 (weak), 2 (moderate) and 3 (strong). The percentage of positive cells (PP) was regarded as 0 (none), 1 ( $\leq 10 \%), 2$ (11-50\%), 3 (51-80\%) and 4 ( $>80 \%$ positive tumour cells). The product of SI and PP is the IRS $(0-12)$. A score of $0-2$ was regarded as negative, $3-12$ as positive [25].

To compare the E-cadherin staining to the normal mucosa, we also used the semiquantitative score established by Blechschmidt et al. for the same purpose [26]. The level of staining intensity was again subdivided into groups ranging from $0-3$. Tumours with less than $20 \%$ of E-cadherin positive cells in category 3 were regarded as downregulated compared to normal colonic mucosa.

\section{Statistical analysis}

Statistical analysis was performed using the SPSS software (Version 18). The threshold for statistical significance was $\mathrm{p}<0.05$. To compare two independent, non-parametric samples we used the Mann-Whitney-U test. All survival analyses were performed using the Kaplan-Meier method. The significance of differences between groups was assessed using the log rank test. The Cox-Regression analysis was used to evaluate the risk of differences between groups in the Kaplan-Meier survival analyses (hazard ratio).

In all boxplots, the boxed area corresponds to the 25 th to 75 th percentile. The horizontal bars indicate the median. The whiskers show the 5th to 95th percentile. All outliers are indicated as dots.

\section{Results}

Snail1 expression and its association with E-cadherin in colorectal cancer

We detected Snail1 in 76\% (191/251) of the 251 samples, while E-cadherin expression was lacking in 39\% (97/250) (Remmele score, Figure 1). In 87\% (217/250), E-cadherin expression was downregulated compared to normal mucosa (Blechschmidt score [26]). We did not detect any correlation in the whole tumour between the expression of Snail1 and loss (Remmele score) $(\mathrm{p}=0.85)$ or even downregulation (Blechschmidt score) $(\mathrm{p}=0.82)$ of $\mathrm{E}$ cadherin (Figures 2, 3). We detected no significant difference in the distribution of E-cadherin in the different tumour compartments (tumour centre, invasion front) and expression of Snail1 in the same compartment.

However, Snail1 positive tumours were significantly correlated with Snail1 positive lymph node metastases $(\mathrm{p}=0.03)$; but in those there was again no significant correlation between Snail1 and loss of E-cadherin ( $\mathrm{p}=0.53)$. 


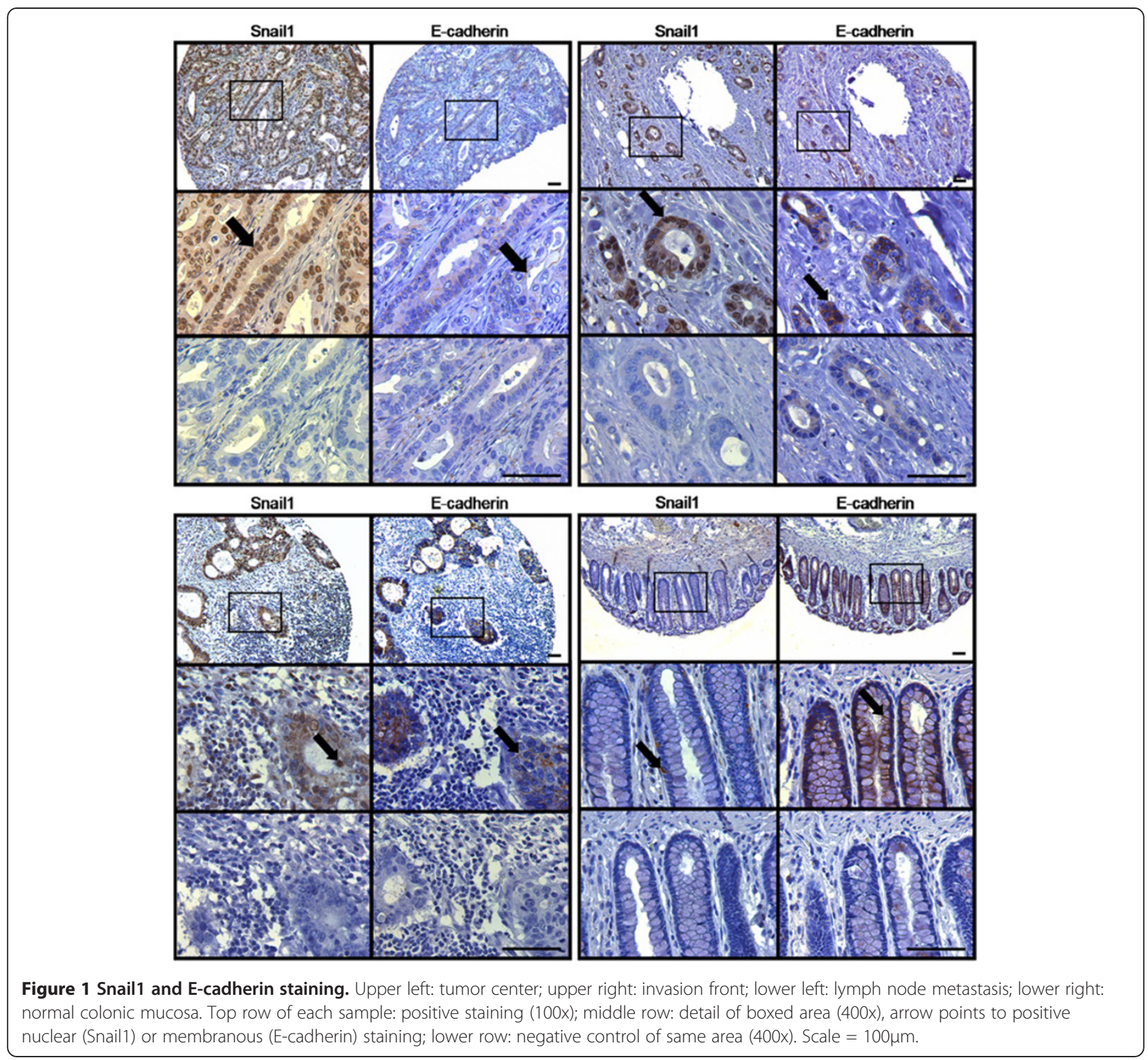

\section{Snail1 and TNM}

Small tumours $(\mathrm{T} 1+\mathrm{T} 2)$ showed a trend towards higher Snail1 expression, compared to advanced tumours $(\mathrm{T} 3+\mathrm{T} 4)(\mathrm{p}=0.077$, Figure $4 \mathrm{~A})$. Although this correlation did not reach significance, when considering the separate compartments, we observed significantly higher expression of Snail1 in the tumour centre of small tumours $(p=0.048$, Figure $4 B)$. Snail1 expression at the invasion front did not differ significantly between small and advanced tumours ( $\mathrm{p}=0.066$, Figure $4 \mathrm{C})$.

Likewise, there was no difference in Snail1 expression between the different $\mathrm{N}$-stages or between low-grade $(\mathrm{G} 1+\mathrm{G} 2)$ and high-grade $(\mathrm{G} 3+\mathrm{G} 4)$ cancer $(\mathrm{p}=0.42$; $\mathrm{p}=0.17$, respectively).

\section{E-cadherin and TNM}

There was a significant difference in E-cadherin expression between low-grade $(\mathrm{G} 1+\mathrm{G} 2)$ and high-grade $(\mathrm{G} 3+\mathrm{G} 4)$ CRC. The high-grade tumours showed significantly reduced E-cadherin expression $(\mathrm{p}=0.03$, Figure 5$)$.

In terms of T-stage, there was no correlation between E-cadherin and small or advanced tumours $(\mathrm{p}=0.17)$.

\section{Influence on overall survival}

Age at diagnosis, lymph node-metastasis $(\mathrm{N})$, tumour stage (T) and grading (G) showed a significant influence on overall survival (Figure 6), while neither Snail1 nor E-cadherin expression seemed to have any effect (Figure 7). Cox-regression analysis of overall survival showed a hazard 


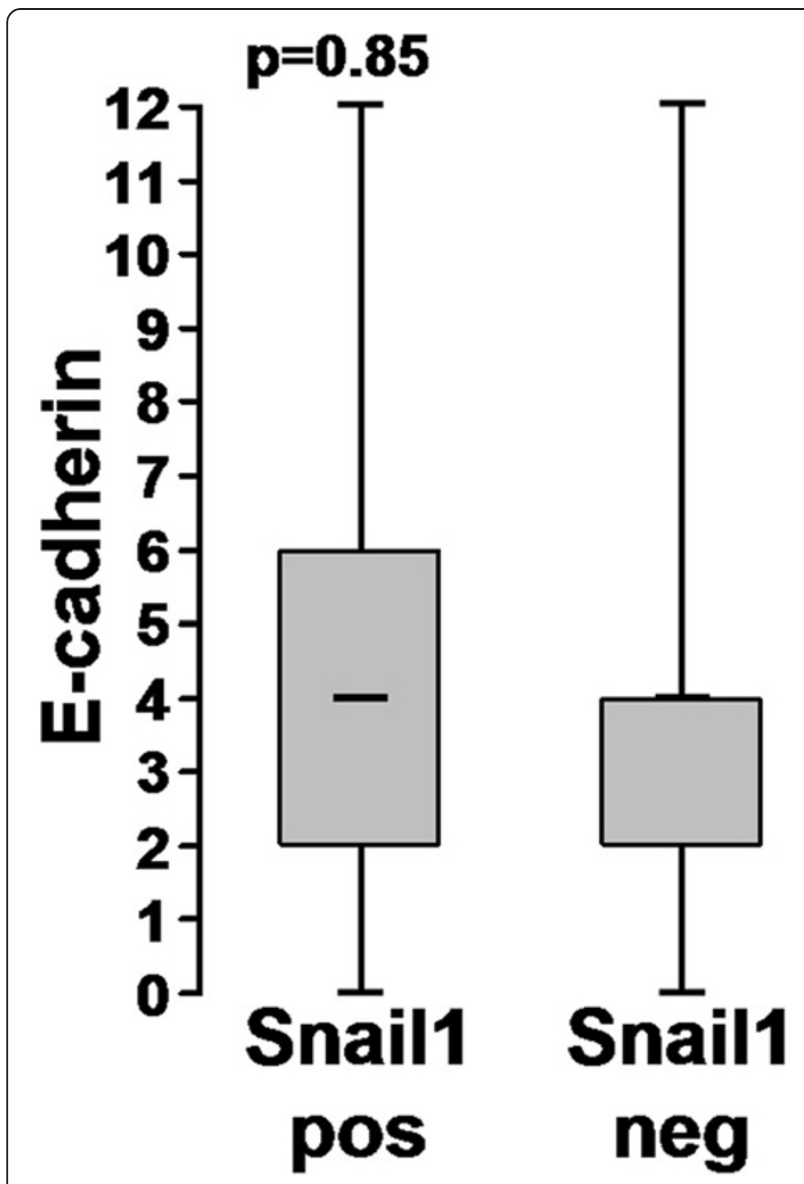

Figure $2 \mathrm{E}$-cadherin staining according to the Remmele score (y-axis) of Snail1 positive and negative tumors ( $x$-axis).

ratio (HR) of 1.7 for lymph node metastases, 1.6 for grading and 3.3 for age at diagnosis $(\mathrm{p}<0.0001, \mathrm{p}=0.045, \mathrm{p}<0.0001$, respectively). There was no significant correlation between $\mathrm{T}$-stage or sex and overall survival $(\mathrm{p}=0.1, \mathrm{p}=1.0$, respectively, Table 3).

\section{Effect of Snail1 and E-cadherin on UICC stage and tumour location}

We found a significant correlation between UICC stage and tumour location $(\mathrm{p}=0.01)$. Tumours with a high UICC stage tended to be located in the right colon, while carcinomas of the left colon showed a lower UICC stage. The UICC stage showed no correlation with either E-cadherin or Snail1 expression. We were also unable to detect any difference in the expression of Snail 1 or E-cadherin between rectal, left or right colon cancers.

\section{Discussion}

Invasion and metastasis are life-limiting aspects of malignant tumours. It has been shown in a variety of studies that cancer cells use EMT to downregulate their cell-cell contacts and become motile and invasive [19].

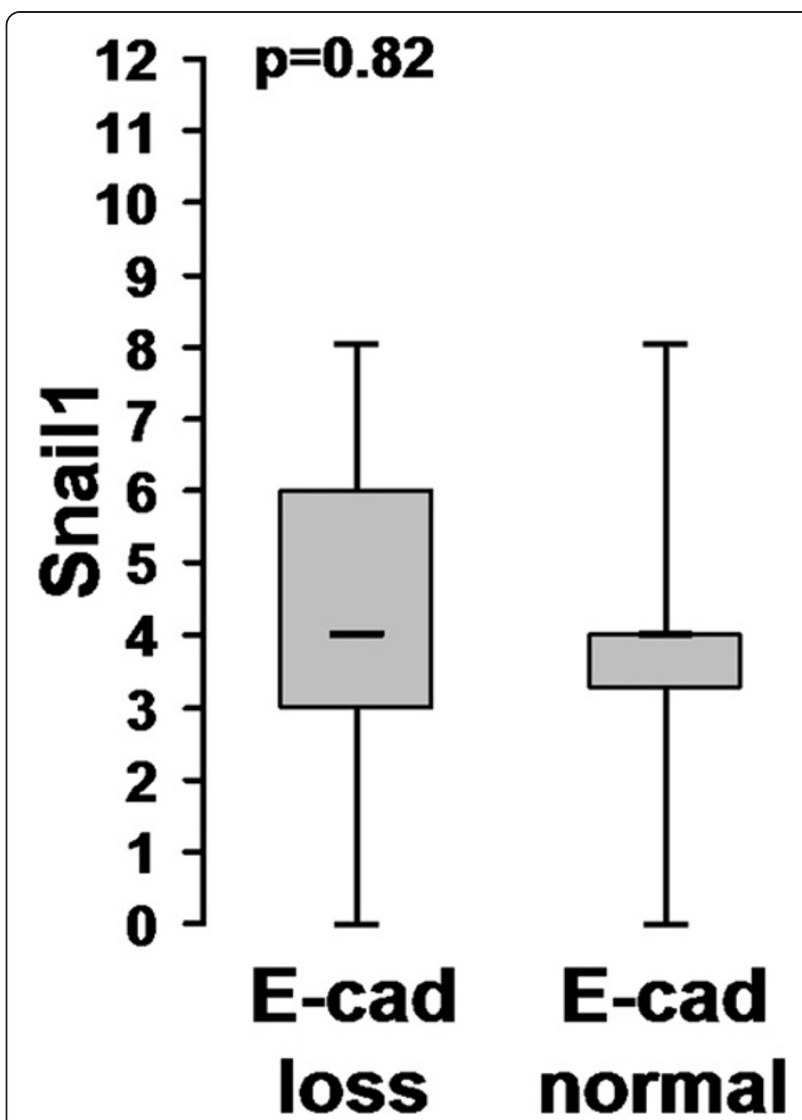

Figure 3 Snail1 staining according to the Remmele score (y-axis) of E-cadherin reduced or normal tumors (x-axis, Blechschmidt score: E-cadherin lost or normal compared to normal colonic mucosa).

Many authors regard EMT as a major mechanism enabling metastasis and initiating the transition between benign and malignant tissue.

Here, we analysed the nuclear expression of Snail1 transcriptional factor in a large cohort of human colorectal carcinomas. Snail1 is one of the best-characterized E-cadherin gene repressors required for triggering EMT. Only cells presenting immunostaining in the nucleus were considered Snail1-positive. The diffuse staining detected occasionally in the cytosol in some epithelial cells was not considered to indicate Snaill expression, since Snail1 is not active in this compartment $[27,28]$.

Conflicting data have been published concerning Snail1 expression in cancer cells and non-malignant epithelium. While Franci et al. found the protein only in carcinoma cells [16], Bezdekova et al. and others found Snail1 expression in normal epithelium $[7,29]$. In a previous study with a much smaller cohort $(n=10)$, we were unable to detect Snail1 mRNA expression in normal colonic tissue [21]. However, in this present analysis Snail1 protein expression was also sporadically detected in single cells in the normal colonic tissue, located at the base of crypts. Colonic 

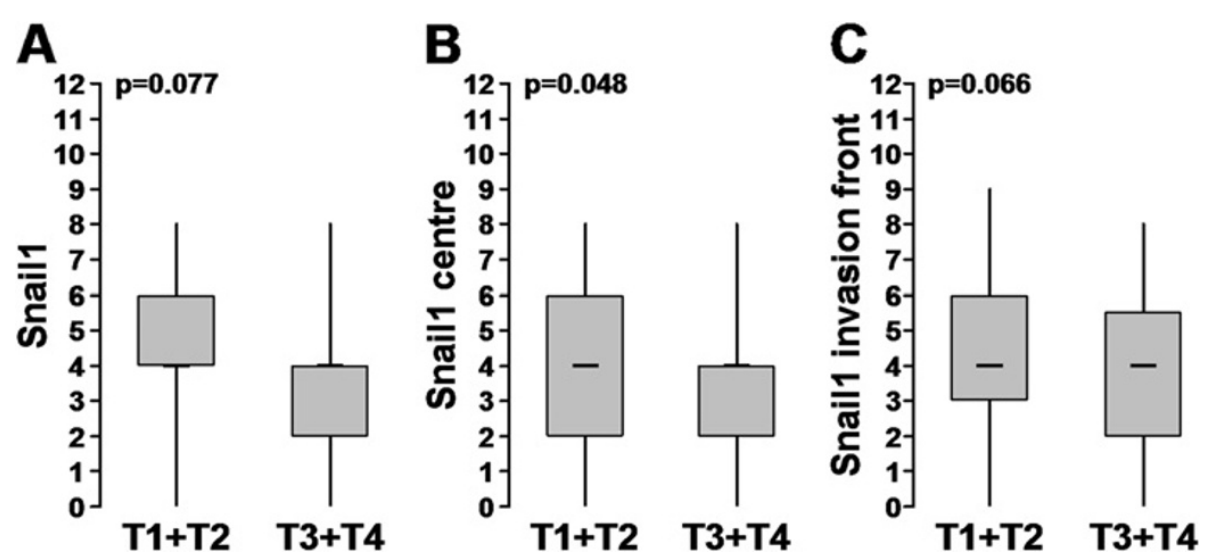

Figure 4 A-C: Different Snail1 staining in small (T1+T2) and advanced (T3+T4) colorectal cancers. Y-axis: Snail1 Remmele score. A: overall tumor; B: Snail1 staining in the tumor center; $\mathbf{C}$ : Snial1 staining in the invasion front.

epithelial stem cells are also believed to be located at the crypt base [30]. Recently, a number of studies have provided evidence that Snaill is involved in the preservation of stem cell function [31-34]. Whether Snail1 is involved in stem cell functions or cell renewal in colon epithelium are questions we can only speculate about.

Analyses of Snail1 gene expression in different types of human tumours indicate that Snail1 is associated

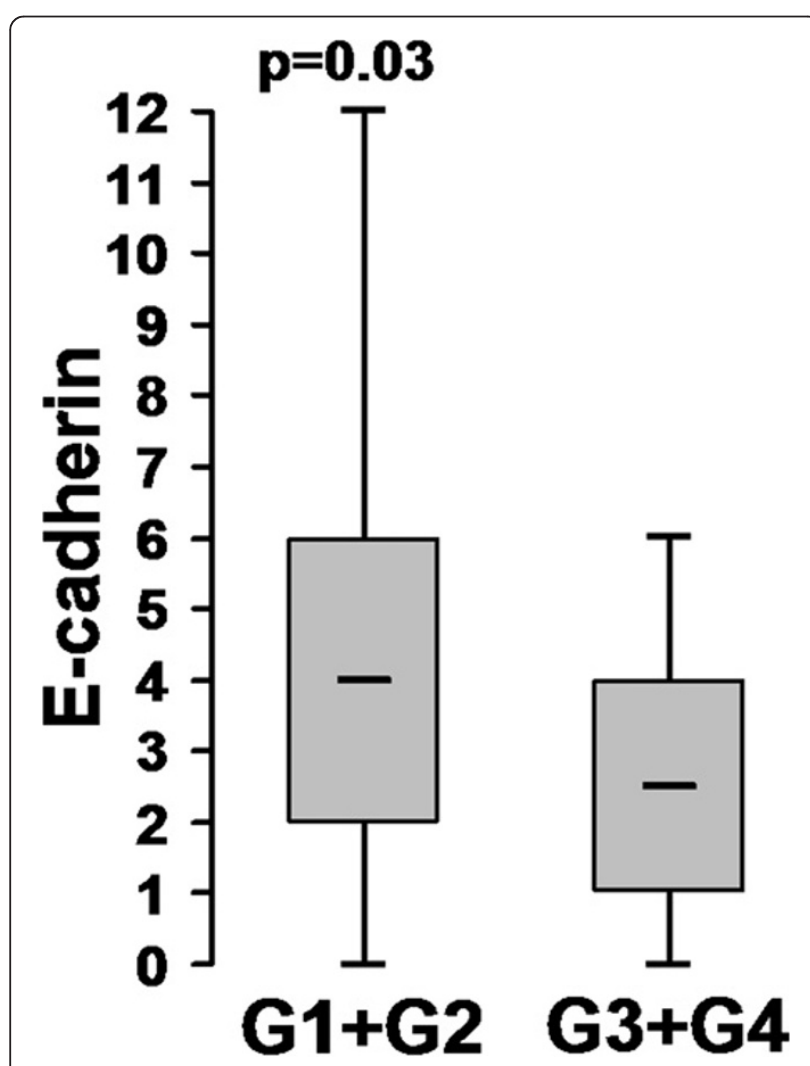

Figure 5 Different E-cadherin staining in low grade $(\mathrm{G} 1+\mathrm{G} 2)$ and high grade $(\mathrm{G} 3+\mathrm{G} 4)$ tumors. Y-axis: E-cadherin Remmele score. with invasion, secondary metastasis and poor prognosis [35-37]. In our present study, Snail1 expression was detected in $76 \%$ of the CRC, similar to previously published expression rates in CRC tissues $[13,16]$. Downregulation of E-cadherin was observed in $87 \%$ of the CRC. The percentage of immunoreactive cells in the samples was variable and heterogeneous for both Snaill and Ecadherin expression. Interestingly, a significant correlation between Snail1 expression and E-cadherin loss was not detectable. However, we detected a significant correlation between the expression of Snail1 in the tumour and Snaill expression in the corresponding lymph node metastasis.

We observed significantly elevated Snail1 expression in the tumour centre of small (T1 and T2) compared to advanced tumours (T3 and 4). This could be attributed to transient Snail1 activation $[6,38]$ in the tumour centre of $\mathrm{T} 1$ and $\mathrm{T} 2$ tumours. There was no difference in Snail1 expression between the T-stages at the invasion front. Snail1 expression at the invasion front was not elevated compared to the tumour centre. Likewise, Snail1 expression was not correlated with histopathological characteristics, such as advanced dedifferentiation (grading) or lymphatic dissemination (N-stage). Interestingly, Franci et al. found higher Snail1 expression at the invasion front of CRC, associated with a significant negative prognostic impact on stage II colon tumours [16]. We noticed a trend between Snaill expression at the invasion front and loss of E-cadherin in the corresponding lymph node metastasis. Furthermore, Snail1 positive tumours were significantly correlated with Snail1 positive lymph node metastases.

The expression of Snail1 in CRC shows variation in the literature. There is evidence that cells from different tumour compartments interact and thus influence the expression of different oncoproteins. This might explain the observed difference in Snail1 expression between the 


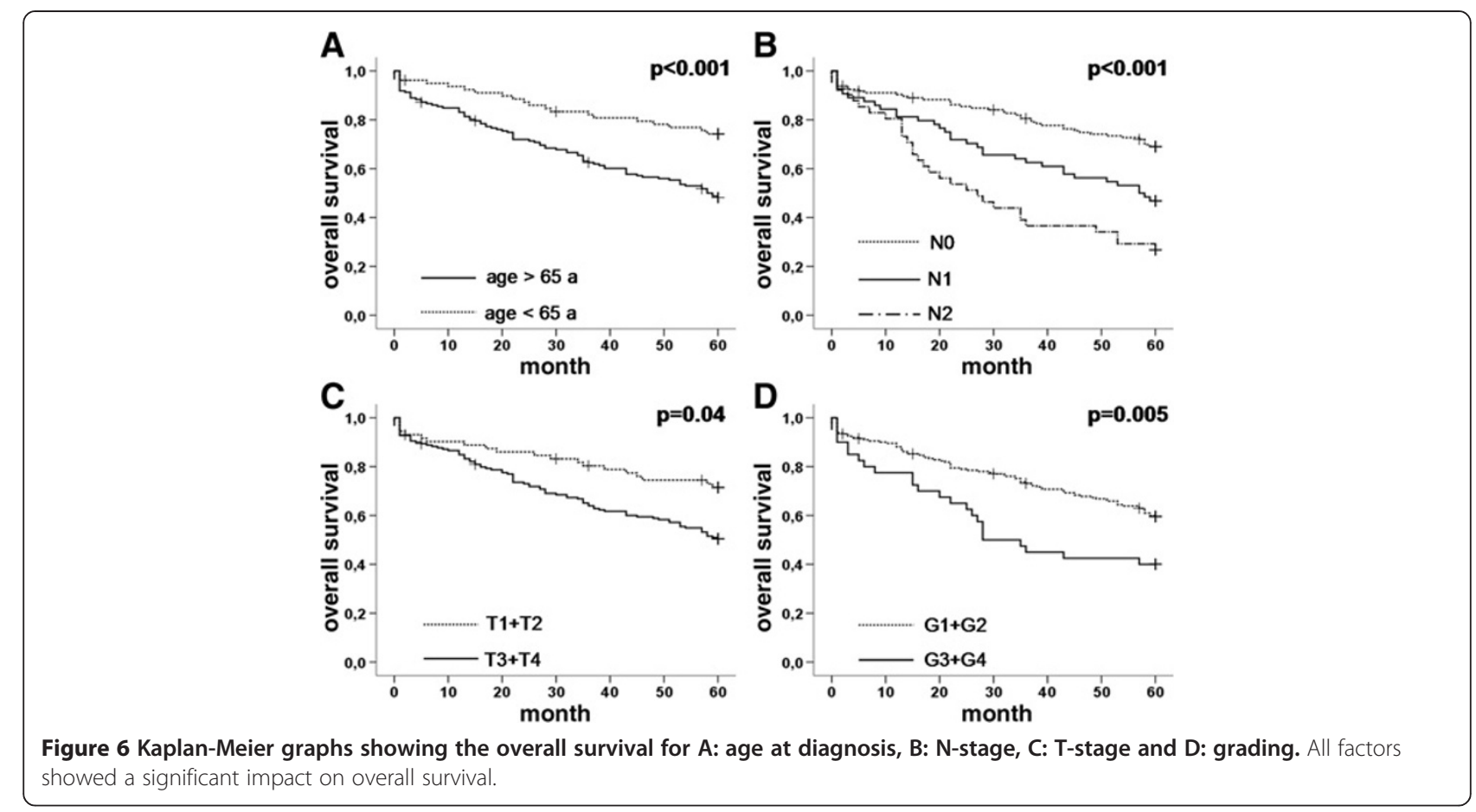

tumour centre, invasion front and microenvironment. Brabletz et al. found [39] beta-catenin overexpression at the invasion front of CRC. In contrast, cells in the tumour centre often showed no nuclear beta-catenin staining. They postulated that regulatory events in the tumour itself could lead to a different distribution of this oncoprotein. It is possible that surrounding tissue at the invasion front can influence tumour cells, leading to nuclear translocation of beta-catenin, where it may play a direct role in tumour invasion processes [39]. Snail1 is postulated to activate EMT pathways like Wnt signalling by binding to beta-catenin, thereby establishing a positive feedback loop for Wnt-dependent transcription [40]. Thus, Wnt signalling and Snail1dependent induction of EMT might be interconnected by multiple positive loops, possibly adding to the robustness of both signalling systems. There is evidence for a close relationship between both pathways in vivo, so the loss of E-cadherin could be attributed to the effects of other EMT pathways, perhaps initially triggered by Snail1 activation $[10,18]$.

Becker et al. studied the expression of Snail1 in adenocarcinomas of the upper gastrointestinal tract and found no evidence of any significant association with clinical and pathological parameters [19]. In addition, the same authors detected an association of Snail1 expression with tumour grade in endometrial carcinomas [41] and with overall survival in ovarian carcinomas [42].

In our study, neither Snail1 nor E-cadherin expression seemed to have an effect on overall survival. Since the association between age and overall survival was very strong in this study, the lack of data on disease-specific
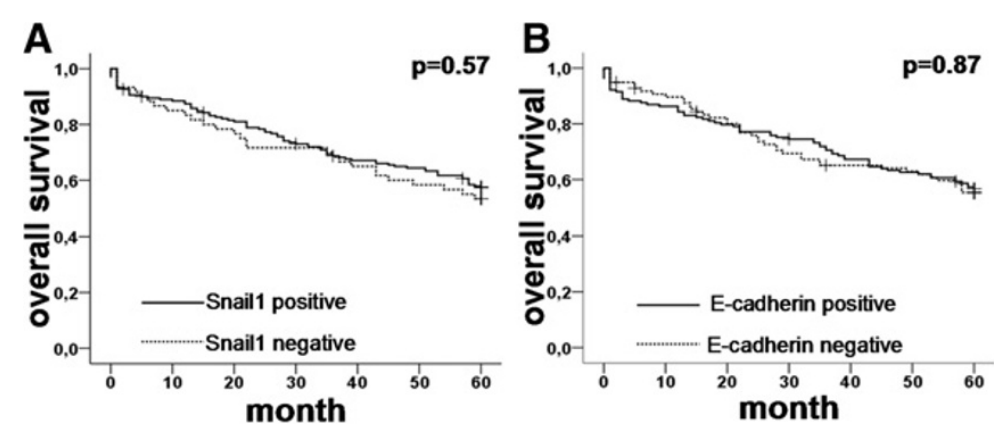

Figure 7 Kaplan-Meier graphs showing the overall survival for A: Snail1 status and B: E-cadherin status. Neither one showed any significant impact on overall survival. 
Table 3 Cox-Regression of clinical parameters

\begin{tabular}{cccc}
\hline COX-Reg & stand. error & P value & HR \\
\hline sex & 0.19 & 0.98 & 1,00 \\
age & 0.25 & $<0.0001$ & 3,32 \\
T & 0.18 & 0.12 & 1,32 \\
N & 0.12 & $<0.0001$ & 1,74 \\
G & 0.22 & 0.04 & 1,56 \\
\hline
\end{tabular}

Stand. error $=$ standard error; $\mathrm{HR}=$ hazard ratio

survival may have led us to underestimate any effects of Snail1 on disease outcome.

Furthermore, we found no evidence of any association of Snail1 with clinicopathological parameters (N-stage, grading, age or sex), with the exception of the significantly elevated Snail1 expression in the tumour centre of small (T1 and T2) compared to advanced (T3 and T4) tumours.

The tumour location, assessed according to the International Classification of Diseases (ICD-10) as endorsed by the WHO, was correlated with the expression profiles of Snail1 and E-cadherin. However, there was no difference in Snail1 expression between rectal, left or right colon cancers.

In conclusion, Snail1 expression was detectable in most of the CRC. Our study indicates that Snail1 expression does not seem to be associated with clinical and pathological data or with overall survival in $\mathrm{CRC}$, even though we cannot rule out an influence on diseasespecific survival. Further investigation to assess the relationship between Snail1 and other EMT markers and its relevance in the progression of CRC might be beneficial.

\section{Conclusion}

Snail1 expression was detectable in most of the CRC but showed no significant association with E-cadherin loss, clinical pathological characteristics or overall survival. The observed loss of E-cadherin could be explained by effects of other important EMT pathways, such as the Wntsignalling cascade.

\section{Competing interests}

There are no financial or other relationships which might lead to a conflict of interest.

\section{Authors' contributions}

FK Made substantial contributions to conception and design of the manuscript, was involved in drafting the manuscript and revising it critically for important intellectual content. G F Shared first authorship. Acquisition of data has been involved in drafting the manuscript and revising it critically for important intellectual content, carried out the immunoassays. SEB analysis and interpretation of immunochemistry data; has been involved in drafting the manuscript or revising it critically for important intellectual content. LD acquisition of data, carried out the immunoassays. AMR acquisition of data analysis and interpretation of immunochemistry data. DH participated in the design of the study and performed the statistical analysis. DV has been involved in drafting the manuscript and revising it critically for important intellectual content; has given final approval of the version to be published.
NHS has made substantial contributions to conception and design, has given final approval of the version to be published. WTK has made substantial contributions to conception and design; has given final approval of the version to be published. All authors read and approved the final manuscript.

\section{Authors' information}

Feride Kroepil and Georg Fluegen are shared first authors.

\section{Acknowledgements}

We thank Imke Hoffmann, Swetlana Seidschner and Sarah Schumacher for suggestions and excellent technical assistance.

\section{Funding}

This study was supported by a grant from the Forschungskommission (grant number 9772354) of the Medical Faculty of Duesseldorf (to F. Kroepil, S.E. Baldus and N.H. Stoecklein).

\section{Author details}

${ }^{1}$ Department of Surgery (A), Heinrich-Heine-University and University Hospital Duesseldorf, Düsseldorf 40225, Germany. ${ }^{2}$ Institute for Pathology, University Hospital Düsseldorf, Düsseldorf, Germany. ${ }^{3}$ Institute for Pharmacology,

Heinrich Heine University of Düsseldorf, Düsseldorf, Germany.

Received: 17 September 2012 Accepted: 14 March 2013

Published: 22 March 2013

\section{References}

1. Batlle E, Sancho E, Franci C, Dominguez D, Monfar M, Baulida J: Garcia De Herreros $A$ : The transcription factor snail is a repressor of $E$-cadherin gene expression in epithelial tumour cells. Nat Cell Biol 2000, 2(2):84-89.

2. Cano A, Perez-Moreno MA, Rodrigo I, Locascio A, Blanco MJ, del Barrio MG, Portillo F, Nieto MA: The transcription factor snail controls epithelialmesenchymal transitions by repressing E-cadherin expression. Nat Cell Biol 2000, 2(2):76-83.

3. van Roy F, Berx G: The cell-cell adhesion molecule E-cadherin. Cell Mol Life Sci 2008, 65(23):3756-3788.

4. Polyak K, Weinberg RA: Transitions between epithelial and mesenchymal states: acquisition of malignant and stem cell traits. Nat Rev Cancer 2009, 9(4):265-273.

5. Roussos ET, Keckesova Z, Haley JD, Epstein DM, Weinberg RA, Condeelis JS: AACR special conference on epithelial-mesenchymal transition and cancer progression and treatment. Cancer Res 2010, 70(19):7360-7364.

6. Thiery JP, Acloque H, Huang RY, Nieto MA: Epithelial-mesenchymal transitions in development and disease. Cell 2009, 139(5):871-890.

7. Bezdekova M, Brychtova S, Sedlakova E, Langova K, Brychta T, Belej K: Analysis of snail-1, e-cadherin and claudin-1 expression in colorectal adenomas and carcinomas. Int J Mol Sci 2012, 13(2):1632-1643.

8. Solanas G, Porta-de-la-Riva M, Agusti C, Casagolda D, Sanchez-Aguilera F, Larriba MJ, Pons F, Peiro S, Escriva M, Munoz A, et al: E-cadherin controls beta-catenin and NF-kappaB transcriptional activity in mesenchymal gene expression. J Cell Sci 2008, 121(Pt 13):2224-2234.

9. Stemmer V, de Craene B, Berx G, Behrens J: Snail promotes Wnt target gene expression and interacts with beta-catenin. Oncogene 2008, 27(37):5075-5080

10. Larriba MJ, Valle N, Palmer HG, Ordonez-Moran P, Alvarez-Diaz S, Becker KF, Gamallo C, de Herreros AG, Gonzalez-Sancho JM, Munoz A: The inhibition of Wnt/beta-catenin signalling by 1alpha,25-dihydroxyvitamin D3 is abrogated by Snail1 in human colon cancer cells. Endocr Relat Cancer 2007, 14(1):141-151.

11. Poser I, Dominguez D, de Herreros AG, Varnai A, Buettner R, Bosserhoff AK: Loss of E-cadherin expression in melanoma cells involves up-regulation of the transcriptional repressor Snail. J Biol Chem 2001, 276(27):24661-24666.

12. Yokoyama K, Kamata N, Hayashi E, Hoteiya T, Ueda N, Fujimoto R, Nagayama M: Reverse correlation of E-cadherin and snail expression in oral squamous cell carcinoma cells in vitro. Oral Oncol 2001, 37(1):65-71.

13. Blanco MJ, Moreno-Bueno G, Sarrio D, Locascio A, Cano A, Palacios J, Nieto MA: Correlation of Snail expression with histological grade and lymph node status in breast carcinomas. Oncogene 2002, 21(20):3241-3246. 
14. Jiao W, Miyazaki K, Kitajima Y: Inverse correlation between E-cadherin and Snail expression in hepatocellular carcinoma cell lines in vitro and in vivo. Br J Cancer 2002, 86(1):98-101.

15. Katoh M: Epithelial-mesenchymal transition in gastric cancer (Review). Int J Oncol 2005, 27(6):1677-1683.

16. Franci C, Gallen M, Alameda F, Baro T, Iglesias M, Virtanen I: Garcia de Herreros A: Snail1 protein in the stroma as a new putative prognosis marker for colon tumours. PLoS One 2009, 4(5):e5595.

17. Peinado H, Olmeda D, Cano A: Snail, Zeb and bHLH factors in tumour progression: an alliance against the epithelial phenotype? Nat Rev Cancer 2007, 7(6):415-428

18. Olmeda D, Jorda M, Peinado H, Fabra A, Cano A: Snail silencing effectively suppresses tumour growth and invasiveness. Oncogene 2007, 26(13):1862-1874

19. Hanahan D, Weinberg RA: Hallmarks of cancer: the next generation. Cell 2011, 144(5):646-674.

20. Loboda A, Nebozhyn MV, Watters JW, Buser CA, Shaw PM, Huang PS, Van't Veer $L$, Tollenaar RA, Jackson DB, Agrawal D, et al: EMT is the dominant program in human colon cancer. BMC Med Genomics 2011, 4:9.

21. Kroepil F, Fluegen G, Totikov Z, Baldus SE, Vay C, Schauer M, Topp SA, Esch JS, Knoefel WT, Stoecklein NH: Down-regulation of CDH1 is associated with expression of SNAI1 in colorectal adenomas. PLoS One 2012, 7(9):e46665.

22. Roy HK, Smyrk TC, Koetsier J, Victor TA, Wali RK: The transcriptional repressor SNAIL is overexpressed in human colon cancer. Dig Dis Sci 2005, 50(1):42-46.

23. Yusra S: S, Yokozaki H: Biological significance of tumor budding at the invasive front of human colorectal carcinoma cells. Int J Oncol 2012, 41(1):201-210.

24. Kononen J, Bubendorf L, Kallioniemi A, Barlund M, Schraml P, Leighton S, Torhorst J, Mihatsch MJ, Sauter G, Kallioniemi OP: Tissue microarrays for high-throughput molecular profiling of tumor specimens. Nat Med 1998, 4(7):844-847.

25. Remmele W, Hildebrand U, Hienz HA, Klein PJ, Vierbuchen M, Behnken LJ, Heicke B, Scheidt E: Comparative histological, histochemical, immunohistochemical and biochemical studies on oestrogen receptors, lectin receptors, and Barr bodies in human breast cancer. Virchows Arch A Pathol Anat Histopathol 1986, 409(2):127-147.

26. Blechschmidt K, Sassen S, Schmalfeldt B, Schuster T, Hofler H, Becker KF: The E-cadherin repressor Snail is associated with lower overall survival of ovarian cancer patients. Br J Cancer 2008, 98(2):489-495.

27. Dominguez D, Montserrat-Sentis B, Virgos-Soler A, Guaita S, Grueso J, Porta M, Puig I, Baulida J, Franci C: Garcia de Herreros A: Phosphorylation regulates the subcellular location and activity of the snail transcriptional repressor. Mol Cell Biol 2003, 23(14):5078-5089.

28. Zhou BP, Deng J, Xia W, Xu J, Li YM, Gunduz M, Hung MC: Dual regulation of Snail by GSK-3beta-mediated phosphorylation in control of epithelialmesenchymal transition. Nat Cell Biol 2004, 6(10):931-940.

29. Zhu Y, Nilsson M, Sundfeldt K: Phenotypic plasticity of the ovarian surface epithelium: TGF-beta 1 induction of epithelial to mesenchymal transition (EMT) in vitro. Endocrinology 2010, 151(11):5497-5505.

30. Samuel S, Walsh R, Webb J, Robins A, Potten C, Mahida YR: Characterization of putative stem cells in isolated human colonic crypt epithelial cells and their interactions with myofibroblasts. Am J Physiol Cell Physiol 2009, 296(2):C296-305

31. Southall TD, Brand AH: Neural stem cell transcriptional networks highlight genes essential for nervous system development. EMBO J 2009, 28(24):3799-3807.

32. Wu Y, Zhou BP: Snail: More than EMT. Cell Adh Migr 2010, 4(2):199-203.

33. Chui MH: Insights into cancer metastasis from a clinicopathologic perspective: Epithelial mesenchymal transition is not a necessary step. Int J Cancer 2012, 132(7):1487-1795.

34. Zhu LF, Hu Y, Yang CC, Xu XH, Ning TY, Wang ZL, Ye JH, Liu LK: Snail overexpression induces an epithelial to mesenchymal transition and cancer stem cell-like properties in SCC9 cells. Lab Invest 2012, 92(5):744-752.

35. Neal CL, Henderson V, Smith BN, McKeithen D, Graham T, Vo BT, OderoMarah VA: Snail transcription factor negatively regulates maspin tumor suppressor in human prostate cancer cells. BMC Cancer 2012, 12(1):336.

36. Fredlund E, Staaf J, Rantala JK, Kallioniemi O, Borg A, Ringner M: The gene expression landscape of breast cancer is shaped by tumor protein p53 status and epithelial-mesenchymal transition. Breast Cancer Res 2012, 14(4):R113.

37. Kawashima A, Takayama H, Kawamura N, Doi N, Sato M, Hatano K, Nagahara A, Uemura M, Nakai Y, Nishimura K, et al: Co-expression of ERCC1 and Snail is a prognostic but not predictive factor of cisplatin-based neoadjuvant chemotherapy for bladder cancer. Oncology letters 2012, 4(1):15-21.

38. Moreno-Bueno G, Portillo F, Cano A: Transcriptional regulation of cell polarity in EMT and cancer. Oncogene 2008, 27(55):6958-6969.

39. Brabletz T, Jung A, Hermann K, Gunther K, Hohenberger W, Kirchner T: Nuclear overexpression of the oncoprotein beta-catenin in colorectal cancer is localized predominantly at the invasion front. Pathol Res Pract 1998, 194(10):701-704

40. Katoh M: Cross-talk of WNT and FGF signaling pathways at GSK3beta to regulate beta-catenin and SNAIL signaling cascades. Cancer Biol Ther 2006, 5(9):1059-1064.

41. Hipp S, Walch A, Schuster T, Losko S, Laux H, Bolton T, Hofler H, Becker KF: Activation of epidermal growth factor receptor results in snail protein but not mRNA overexpression in endometrial cancer. J Cell Mol Med 2009, 13(9B):3858-3867.

42. Hipp S, Berg D, Ergin B, Schuster T, Hapfelmeier A, Walch A, Avril S, Schmalfeldt B, Hofler $H$, Becker KF: Interaction of Snail and p38 mitogenactivated protein kinase results in shorter overall survival of ovarian cancer patients. Virchows Arch 2010, 457(6):705-713.

doi:10.1186/1471-2407-13-145

Cite this article as: Kroepil et al.: Snail1 expression in colorectal cancer and its correlation with clinical and pathological parameters. BMC Cancer 2013 13:145

\section{Submit your next manuscript to BioMed Central and take full advantage of:}

- Convenient online submission

- Thorough peer review

- No space constraints or color figure charges

- Immediate publication on acceptance

- Inclusion in PubMed, CAS, Scopus and Google Scholar

- Research which is freely available for redistribution 